\title{
Control of Gain and SAR for Wearable Antenna Using AMC Structure
}

\author{
Pujayita SAHA, Debasis MITRA, Susanta K. PARUI \\ Dept. of Electronics and Telecommunication Engineering, IIEST, Kolkata, India \\ pujayita.2010@gmail.com
}

Submitted June 26, 2020 / Accepted January 19, 2021

\begin{abstract}
Herein, a compact, low profile flexible wearable antenna with an AMC (Artificial Magnetic Conductor) embedded structure is presented. The proposed AMC-integrated antenna is fabricated using layers of leather and operates at the Industrial Scientific Medical (ISM) $5.8 \mathrm{GHz}$ band. The overall dimension of the low-profile AMC antenna is $40.5 \times 40.5 \times 6 \mathrm{~mm}^{3}$. AMC structure is incorporated to reduce the backward scattering wave toward the human body which in turn increases the gain to $7.47 \mathrm{~dB}$ and reduces the specific absorption rate (SAR) about 90\%. The fabricated antenna prototype with the integrated AMC is investigated by placing it on different parts of the human body. The performance studies of the AMC backed antenna also reveal that it can tolerate the loading due to the bent surface as well as the crumpled surface. The obtained results show that the proposed antenna is safe and suitable for biomedical applications.
\end{abstract}

\section{Keywords}

Artificial Magnetic Conductor (AMC), flexible antenna, leather antenna, wearable antenna, biomedical application

\section{Introduction}

Exhaustive research activities are being done for the advancement of the medical measurement systems in recent years. Consequently, wearable electronics is gaining interest in the increasing number of healthcare monitoring systems for continuous monitoring of patient's health parameters [1]. Wearable antennas, being an essential part of the wearable devices, invites extensive studies in recent times [2], [3]. Researchers pay special attention to the physical comfort of the wearable antennas that have to be integrated with clothing. Some research works have already been done on flexible materials such as textile [4-10], PDMS [11] (polydimethylsiloxane), leather [12], [13] as the substrate for these antennas. Usually, wearable antennas offer high flexibility but also introduce losses caused by the human body as it is a lossy, dispersive material with a high dielectric constant that absorbs a large amount of the radiated electromagnetic power from the antenna. Consequently, the gain of the antennas falls remarkably and a harsh distortion in radiation pattern is observed when the antennas are positioned proximate to a human body [14]. These nosy effects have been contemplated as well as the gain enhancement has been realized while designing the wearable antennas for body-worn applications [15]. Another important aspect to be considered is the value of specific absorption rate (SAR) which is strongly affected by the coupling and absorption by the human body tissues. To control the SAR value within a standard SAR limit two different polymetric ferrite sheets have been used as protective shielding while designing the antenna [16]. Quite a few techniques have been adopted to reduce the SAR value as well as the increase of gain value in recent works.

Combining Electromagnetic Band Gap structures (EBGs) [4, 9, 10], Artificial Magnetic Conductors (AMCs) $[7,8,17-19]$ as a backing shield to the wearable antenna is the common approache for simultaneously SAR reduction and gain enhancement. AMC back shield minimizes the surface wave and also significantly reduces radiation towards the human body surface. As a result, the antenna exhibits an improvement in its overall gain. Meanwhile, as a wearable antenna might contort or bend when worn, it must be designed in such a way so that it not to be sensitive toward deformations. The monopole antenna [7], [8] which is robust with respect to the resonance frequency, placed over an AMC layer, presenting marginal changes due to structural deformation. However, those antennas were too large to fit into the wearable applications. Consequently, the attention of research moved to smaller designs.

In this design, a leather substrate-based CPW (coplanar waveguide) fed wearable antenna backed by a simple AMC structure is proposed operating in ISM $(5.8 \mathrm{GHz})$ band. Though the leather is a lossy material, yet has been chosen as substrate owing to its wide application in the fashion industry like leather made jacket, wrist band, cap, belt, gloves, etc. Also due to its flexibility, it can be a good choice for wearable electronics. The proposed AMC backed leather antenna attained a high gain value of $7.47 \mathrm{~dB}$ which is quite acceptable in the wearable applications. The AMC structure comprises of simple square patch 
surrounded by a square ring-shaped unit cell. It is also observed that around 90\% SAR reduction is achieved in the proposed AMC backed antenna with respect to the without AMC antenna. The proposed AMC backed antenna is proven in different robust conditions like bent and crumpled surface. Furthermore, SAR analysis is accomplished by placing the antenna on a different parts of the human body phantom. The simulated results are further validated both for with $\mathrm{AMC}$ and without AMC antenna.

\section{Antenna and AMC Structure Design}

\subsection{Antenna Configuration}

The layout of the proposed CPW fed flexible wearable antenna is shown in Fig. 1 and its fabricated prototype is depicted in Fig. 2. Leather, being a flexible material, is chosen here as the substrate so that the proposed antenna can be easily integrated with wearable accessories like jacket, hand band, cap etc. The dimension of the leather material is $\mathrm{L} \times \mathrm{W}$, thickness $2 \mathrm{~mm}$ and its permittivity and loss tangent are 2.75 and 0.02 , respectively. The conductive part of the antenna is realized with self-adhesive copper tape with thickness of $0.05 \mathrm{~mm}$. A piece of foam with a permittivity close to air is used between the antenna and the AMC to fill the gap among them.

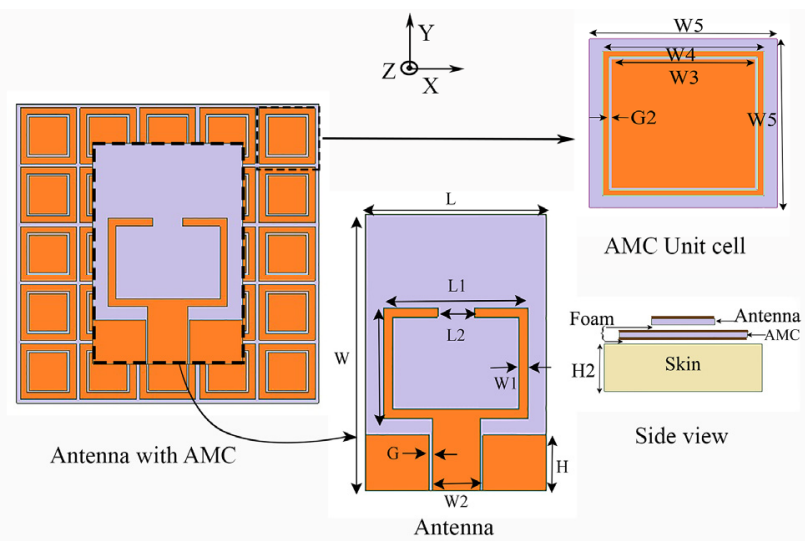

Fig. 1. Geometry of the proposed antenna and AMC structure. The optimized dimensions in millimeters are $\mathrm{L}=20$, $\mathrm{W}=30, \mathrm{~L} 1=16, \mathrm{~L} 2=4, \mathrm{~W} 1=1, \mathrm{~W} 2=5.3, \mathrm{G}=0.3, \mathrm{H}=6$, $\mathrm{W} 3=5.1, \mathrm{~W} 4=7.5, \mathrm{~W} 5=8, \mathrm{G} 2=0.3$.

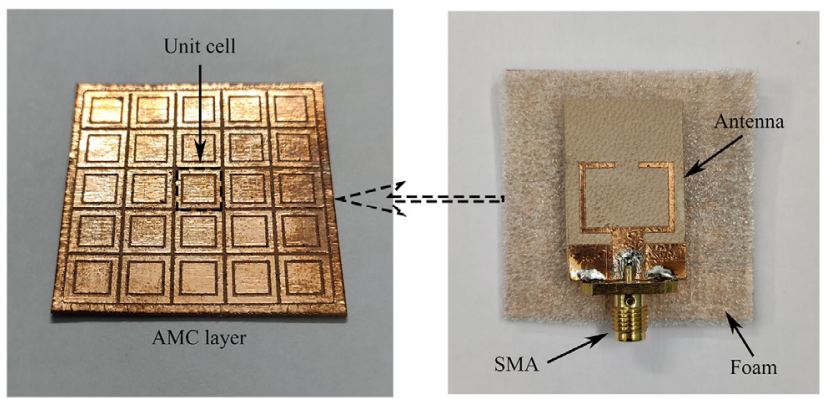

Fig. 2. Fabricated prototype of the proposed antenna.

\subsection{AMC Design}

It is a well-known fact that in a normally incident plane wave, a reflection phase of $180^{\circ}$ occurs while reflected from a Perfect Electric Conductor (PEC) whereas a $0^{\circ}$ reflection phase is realized while reflected from a Perfect Magnetic Conductor (PMC). Hence, an antenna current appears in PEC ground plane and its image currents cancel each other, which leads the real part of the impedance towards zero and the imaginary part near infinity, according to image theory. Henceforth, a significant amount of fall in efficiency is observed due to the trapping of energy between antenna and ground plane [19]. However, if the AMC ground plane is used instead of PEC the opposite scenario is observed due to its in-phase reflection characteristics and hence the gain of the antenna increases as well as the undesired exposure of EM radiation to the human body can be eliminated.

The structure of the rectangular ring-shaped AMC unit cell is shown in Fig. 1. The variation of reflection phase with frequency for different W4 and W5 are shown in Fig. 3. In the proposed AMC unit cell, the exact zeroreflection phase point is at $5.8 \mathrm{GHz}$ for $\mathrm{W} 4=7.5 \mathrm{~mm}$ and $\mathrm{W} 5=8 \mathrm{~mm}$. It is worth mentioning that in the simulation phase, the AMC array was enlarged by one row and one column at a time until an acceptable performance was achieved in ISM $5.8 \mathrm{GHz}$ frequency band in terms of high gain and low SAR. The optimized result is achieved with $5 \times 5$ AMC array. The achieved bandwidth within $\pm 90^{\circ}$ phase values is $910 \mathrm{MHz}(5.29-6.20 \mathrm{GHz})$. AMC consists of three segments 1) an outer square metal ring, 2) an inner square metal patch on the dielectric substrate and 3) one more metal layer as the ground plane at the bottom of the substrate. Here also leather is used as the AMC substrate. AMC is fabricated by the LPKF Proto Mat S64.

\section{Results and Discussion}

\subsection{Antenna Performance on Skin Phantom}

A skin phantom of height $5 \mathrm{~mm}, \varepsilon_{\mathrm{r}}=38.62$ and $\sigma=$ $4.342 \mathrm{~S} / \mathrm{m}$, at $5.8 \mathrm{GHz}$ [20] is considered here to imitate the human tissue environment during simulation as shown in Fig. 1. The simulated and measured $S_{11}$ characteristics with and without the AMC is shown in Fig. 4. It shows a feasible settlement between simulated and measured results below $-10 \mathrm{~dB}$. The measured impedance bandwidth of the antenna without $\mathrm{AMC}$ is $440 \mathrm{MHz}(5.56-6.0 \mathrm{GHz})$ with the resonance frequency of $5.75 \mathrm{GHz}$ which is close to the simulated impedance bandwidth $560 \mathrm{MHz}(5.5-6.06 \mathrm{GHz})$ with the resonance frequency of $5.8 \mathrm{GHz}$. Whereas the measured impedance bandwidth of the AMC-backed antenna is $510 \mathrm{MHz}(5.56-6.07 \mathrm{GHz})$ with resonance frequency of $5.78 \mathrm{GHz}$ and the corresponding simulated one is $520 \mathrm{MHz}(5.56-6.08 \mathrm{GHz})$ with resonance frequency of $5.79 \mathrm{GHz}$. There is a minor shift in the measured and sim- 
ulated $\mathrm{S}_{11}$ characteristics of the antenna with AMC and without AMC. This difference could be due to the precision of the fabrication process. Antenna with AMC displays improved impedance matching compared to antenna alone.

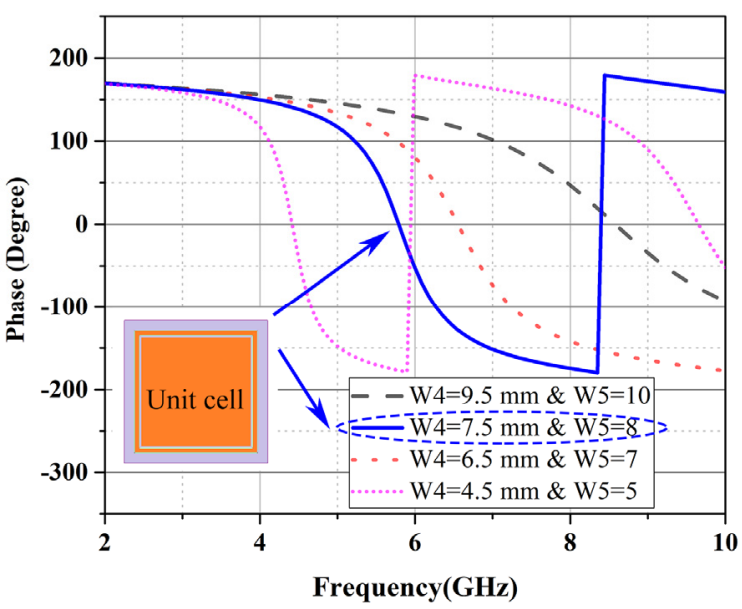

Fig. 3. Reflection phase characteristics of the proposed AMC.

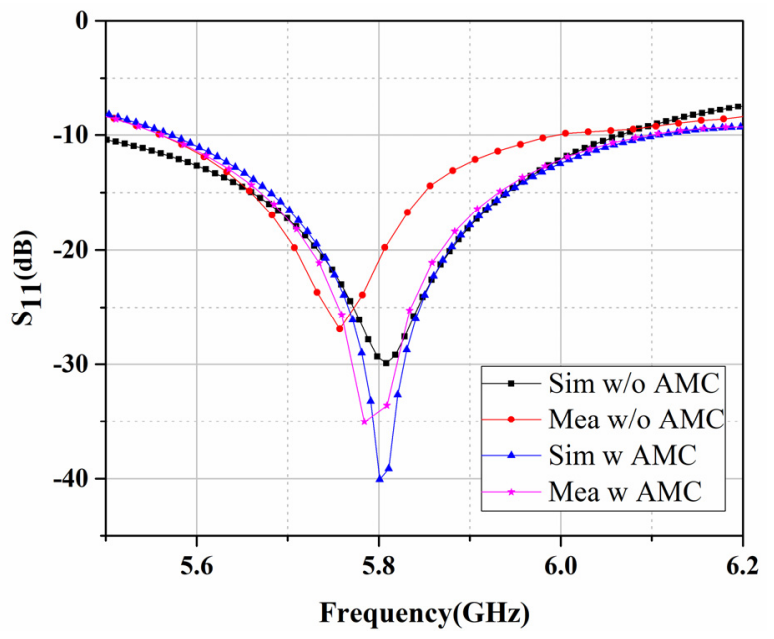

Fig. 4. Reflection co-efficient characteristics of the antenna with and without AMC.

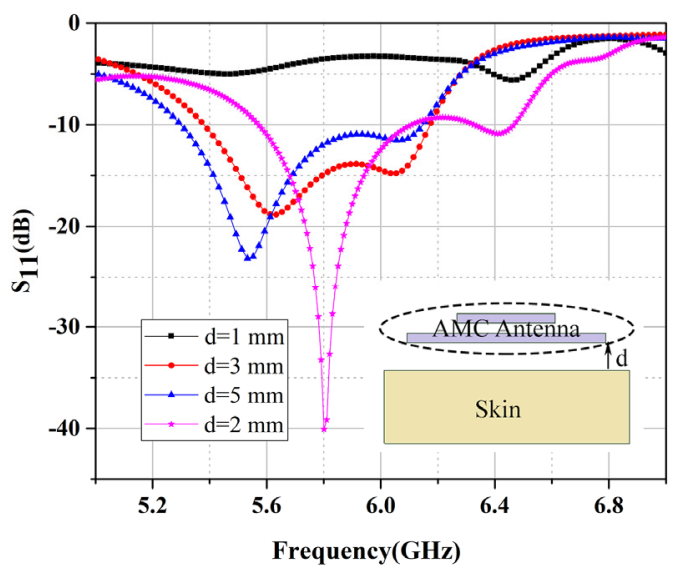

Fig. 5. Reflection coefficient characteristics of the proposed antenna for different distance from the human skin phantom.
Figure 5 represents a parametric analysis of the separation $(d)$ between the AMC antenna and skin phantom and its effect on the antenna return loss. It is obvious that the high impedance matching performance of the antenna at $5.8 \mathrm{GHz}$ is achieved at a separation of $2 \mathrm{~mm}$. The design also ensures the compact overall dimension.

The normalized far-field radiation patterns of the antenna without $\mathrm{AMC}$ and with $\mathrm{AMC}$ at $5.8 \mathrm{GHz}$ are depicted in Fig. 6. The measured radiation patterns in both $x z$ and $y z$ planes along with the gain values settle well with the simulated results, for both the antennas. The measured gain for the proposed AMC backed antenna is $7.47 \mathrm{~dB}$ compared to $4.03 \mathrm{~dB}$ for the antenna without AMC. The simulated gains were $7.84 \mathrm{~dB}$ for $\mathrm{AMC}$ backed antenna and $6.37 \mathrm{~dB}$ for the antenna without AMC. The increase in the FBR (Front to Back Ratio) was achieved by the inphase reflection property of the AMC structure.

\subsection{On Body Antenna Performance}

After analyzing the AMC integrated antenna in skin phantom, this section studies the effect of human body on

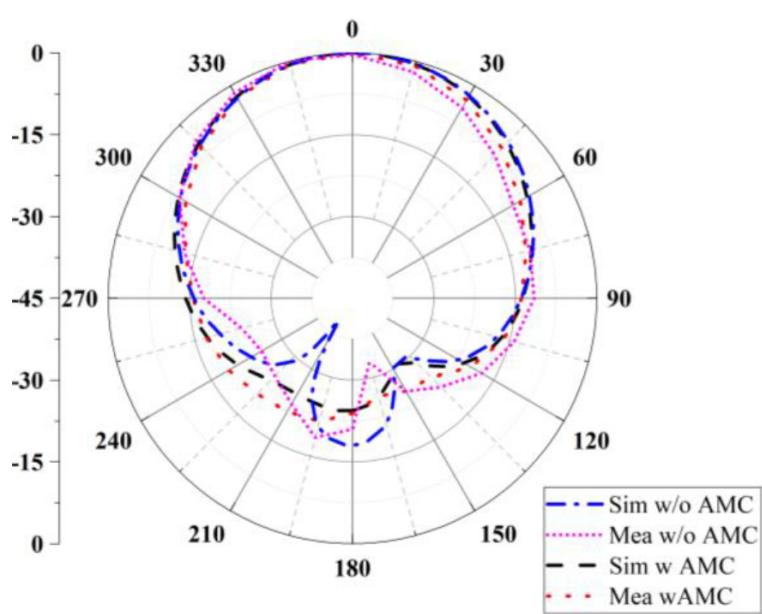

(a)

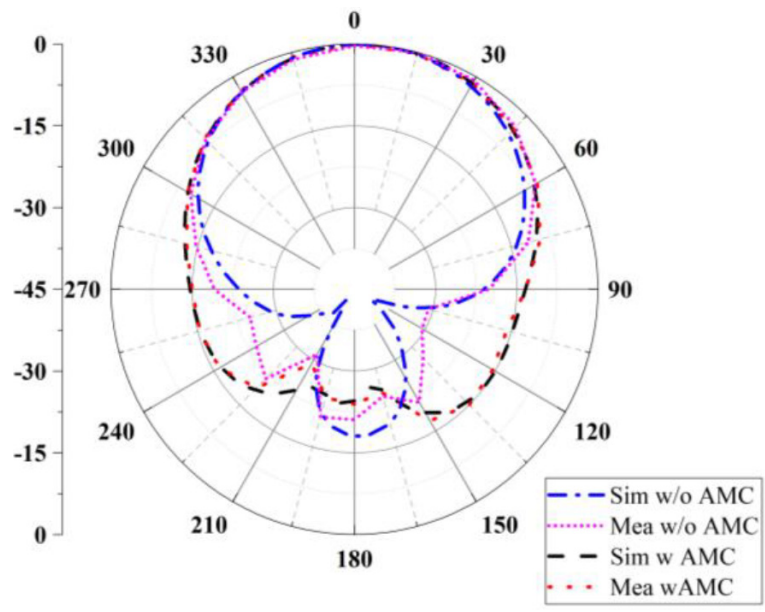

(b)

Fig. 6. Normalized far-field radiation patterns without AMC and with AMC backed antennas in (a) $x z$ plane (b) $y z$ plane. 
the refection coefficient of the proposed antenna. Figure 7 shows that the AMC backed antenna is placed on the different parts of a human body (male arm, head and chest). Also the antenna performance characteristics are observed in Fig. 8. Minimum shift of resonance frequency is observed in simulated and measured reflection co-efficient characteristics for all the three cases. It is also observed that the resonant frequency of the impedance characteristics of the AMC antenna is slightly left shifted while placed over the human head and impedance matching marginally degraded due to high dielectric constant. The proposed antenna covers the entire desired band for all the three cases and hence can be inferred that the antenna will deliver acceptable performance irrespective of its placement on the human body.

When the antenna is combined with the AMC reflector the gain of the antenna is increased over entire operating band in free space and as well as in the presence of human body as shown in Fig. 9. The efficiency of the proposed AMC antenna in presence of human body remains comparable with its free space efficiency as shown in Fig. 10. It indicates that the AMC reflector efficiently isolates the radiating antenna from the human body phantom.
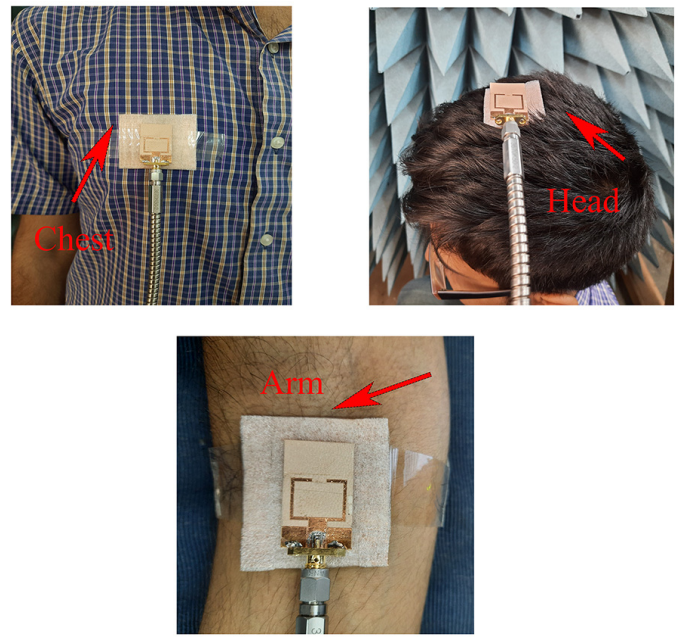

Fig. 7. AMC backed antenna placement on different parts of human body.

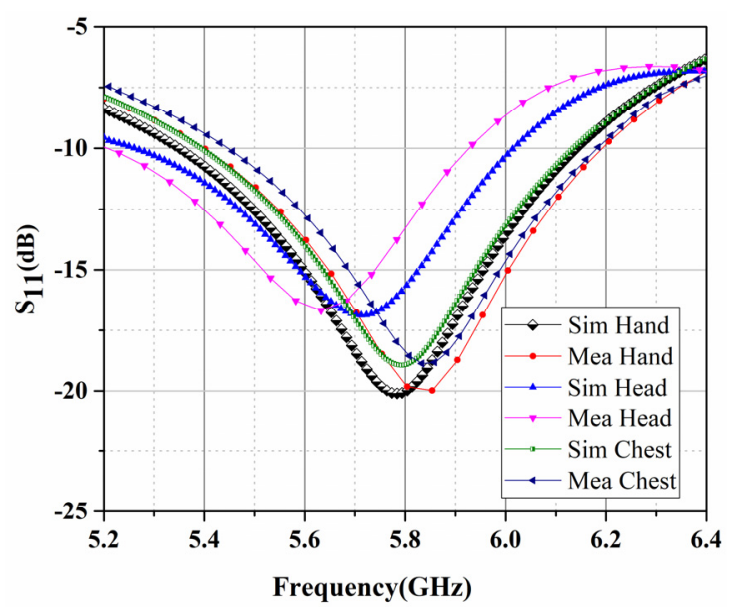

Fig. 8. Reflection coefficient behavior on human body.

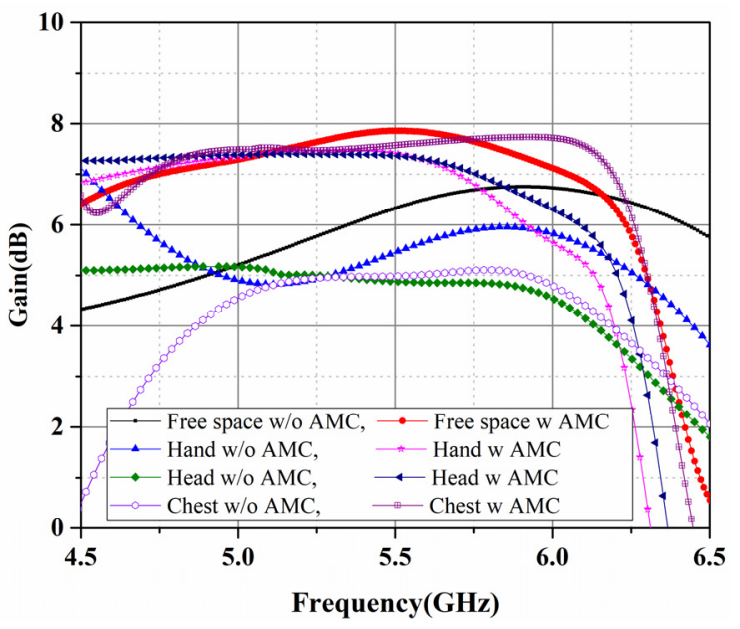

Fig. 9. Gain behavior with frequency for the without AMC antenna and the AMC antenna on free space and human body.

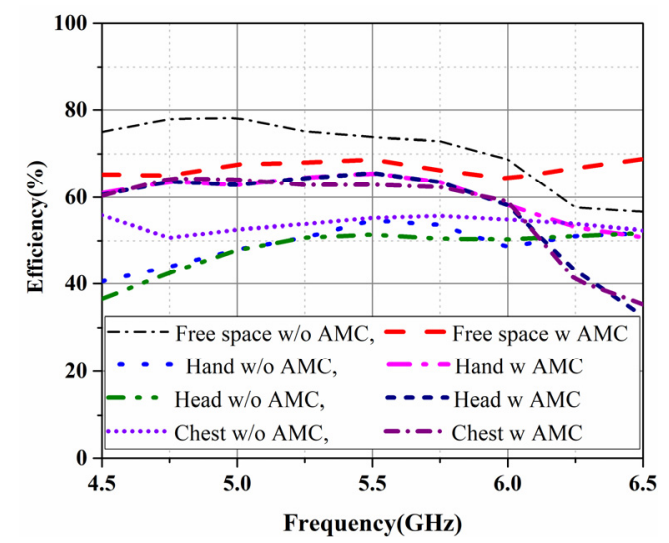

Fig. 10. Efficiency behavior with frequency for the without $\mathrm{AMC}$ antenna and the AMC antenna on free space and human body.

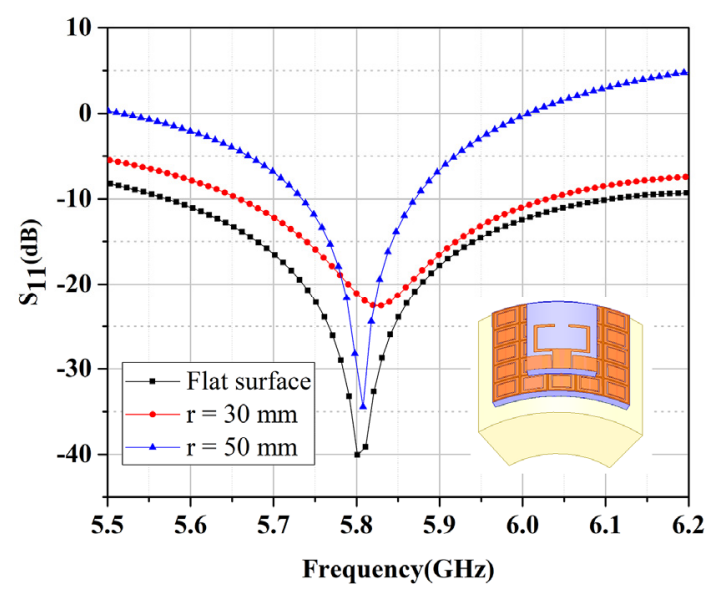

Fig. 11. $S_{11}$ of the proposed antenna in different bending conditions.

\subsection{Performance of AMC Antenna on Bent Surface}

Though, bending effect degrades the antenna performance is unavoidable for a wearable antenna. So, for 
wearable antennas, a suitable structure of the antenna is necessary to combat with such bending situations. The proposed antenna performs satisfactorily under considered bending conditions. Figure 11 shows the impedance characteristics of the proposed antenna under the different bending conditions. Both of the cases with bending radius $\mathrm{r}=30 \mathrm{~mm}$ and $\mathrm{r}=50 \mathrm{~mm}$, the proposed antenna exhibits acceptable operational bandwidth reduction with ignorable shift in resonant frequency.

\subsection{Performance of AMC Antenna on Crumpled Surface}

The performance of the proposed wearable antenna is further studied for the crumpled surface also. For crumpled surface analysis, $a$ (crumple depth) $=6 \mathrm{~mm}$ and $b$ (peak distance between the two troughs) $=16 \mathrm{~mm}$ were chosen. The corresponding reflection co-efficient characteristic of the antenna for the crumpled surface is depicted in Fig. 12. It is observed from the figure that under crumpled condition, the antenna impedance matching suffered an acceptable degradation but the entire desire ISM is covered. Moreover, the crumpled antenna accomplished a wider bandwidth than the flat antenna.

\subsection{SAR Performance}

SAR is a crucial indicator to estimate the real world performance of a wearable antenna. It is the rate at which energy is absorbed by the human body when bare to an electromagnetic field. The maximum SAR limit is $1.6 \mathrm{~W} / \mathrm{kg}$ for any $1 \mathrm{~g}$ tissue according to federal communications commission (FCC) or $2 \mathrm{~W} / \mathrm{kg}$ for any $10 \mathrm{~g}$ tissue by the International Commission on Non-Ionizing Radiation Protection (ICNIRP) standard. It is obvious from Fig. 13 that for the $1 \mathrm{~W}$ input power, the proposed AMC backed antenna realized a SAR value of $4.0 \mathrm{~W} / \mathrm{kg}$ while the same antenna without AMC experiences $46.9 \mathrm{~W} / \mathrm{kg}$ for $1 \mathrm{gm}$ human skin tissues. Thus, the proposed design achieved around $90 \%$ reduction in SAR. The SAR distributions calculated when the AMC antenna is placed at $2 \mathrm{~mm}$ distance from the skin phantom. Hence, in order to satisfy the most restrictive SAR regulation (i.e., $\mathrm{SAR}<1.6 \mathrm{~W} / \mathrm{kg}$ ), the input power must be limited to $410 \mathrm{~mW}$ for $1 \mathrm{gm}$ skin tissue model.

Peak SAR values recorded are $40.39 \mathrm{~W} / \mathrm{kg}$, $26.81 \mathrm{~W} / \mathrm{kg}$ and $56.69 \mathrm{~W} / \mathrm{kg}$ for $1-\mathrm{g}$ tissue of hand, chest and head respectively for without AMC antenna powered by $1 \mathrm{~W}$ at the input as shown in Fig. 14. The antenna SAR improves to $5.86 \mathrm{~W} / \mathrm{kg}, 3.0 \mathrm{~W} / \mathrm{kg}$ and $6.28 \mathrm{~W} / \mathrm{kg}$ with $1 \mathrm{~W}$ input power for 1-g tissue for the AMC antenna configuration when the antenna is allocated on hand, chest, head correspondingly (Fig. 15). For the three different body locations, peak SAR values achieved from the simulations are different, as the tissue depths and distributions are different for the body parts of hand, chest and head. It is observed from the SAR values that the input power of the AMC antenna should be limited to $255 \mathrm{~mW}$ to have

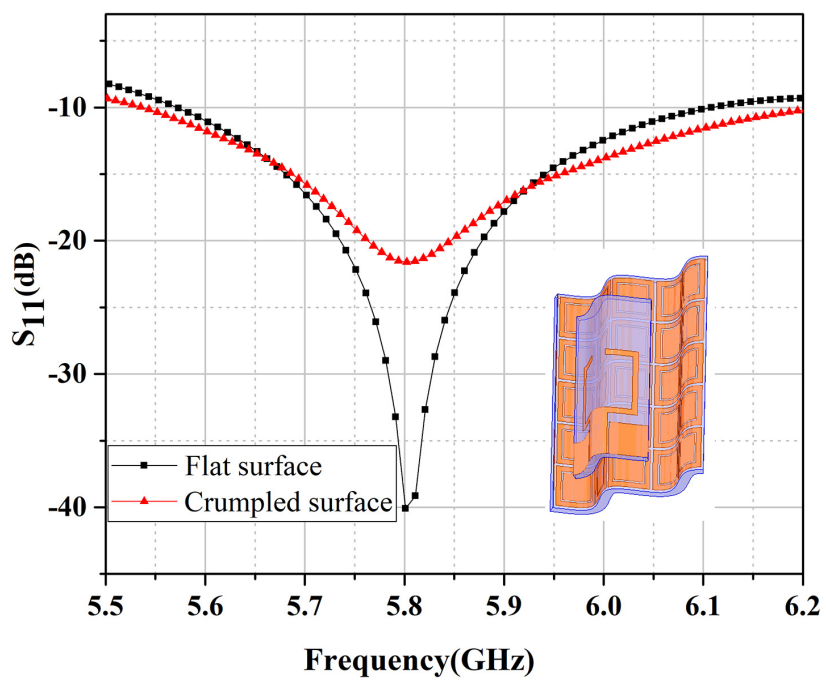

Fig. 12. $S_{11}$ of the proposed antenna in different crumpled surface.

1.6 W/kg SAR irrespective of the location of the antenna. The achieved SAR levels of the AMC antenna are within the certain limits permissible by the above-mentioned standards. To reduce the simulation time, a portion of the torso model is selected instead of simulating the entire numerical model.

Table 1 compares the properties of the proposed AMC antenna with those of the other similar reported wearable antennas operating in $5.8 \mathrm{GHz}$ band. As observed in [21], the antenna is fabricated on a rigid substrate which is uncomfortable to the users in wearable technology. Moreover, the overall thickness of the antenna is troublesome for wearable application. It is observed from the table that the size of the proposed antenna is small compared to others flexible antennas [8], [13]. As well as it achieved the highest gain among the other reported antennas $[8,13,21]$ despite of the use of lossy material as a substrate. Furthermore, the SAR value of the proposed antenna is reduced appreciably using the AMC in the back, whereas in [13] the SAR value is increased with use of EBG shielding in the back.

\section{Conclusion}

An AMC backed wearable leather antenna working in the $5.8 \mathrm{GHz}$ ISM band is proposed in this paper. The antenna and AMC are designed on leather substrate that can be combined with our daily clothes. The proposed antenna has satisfactory impedance matching in the $5.8 \mathrm{GHz}$ ISM band, and its refection coefficient remains stable in various structural deformations like crumpling and bending circumstances. Moreover, the proposed antenna exhibits acceptable SAR value with a $90 \%$ reduction compared to the antenna alone. Additionally, the design shows a minute susceptibility to performance degradation in terms of return loss and SAR when loaded with human body. The proposed AMC-backed wearable antenna is an acceptable candidate for biomedical applications. 


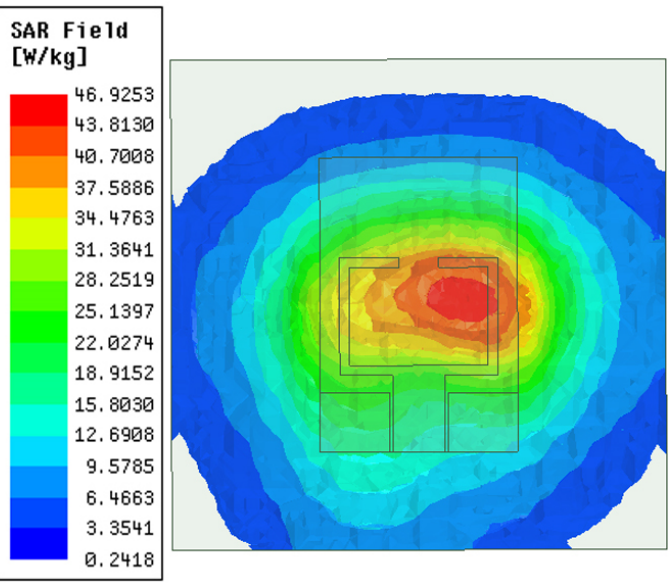

(a)

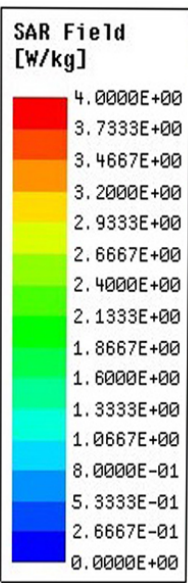

$0.0000 \mathrm{E}+00$

Fig. 13. SAR of the proposed antenna: (a) without AMC, (b) with AMC.

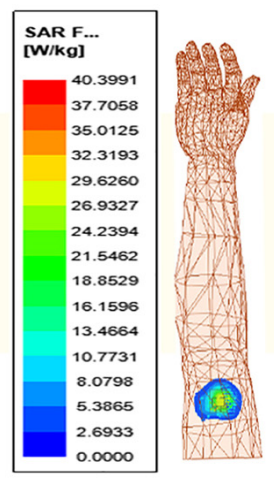

(a)

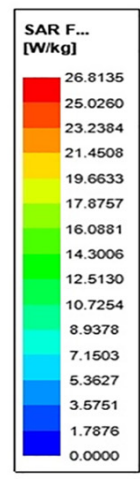

.0000

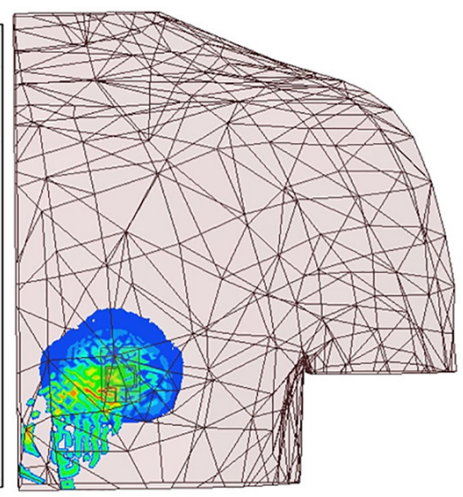

(b)

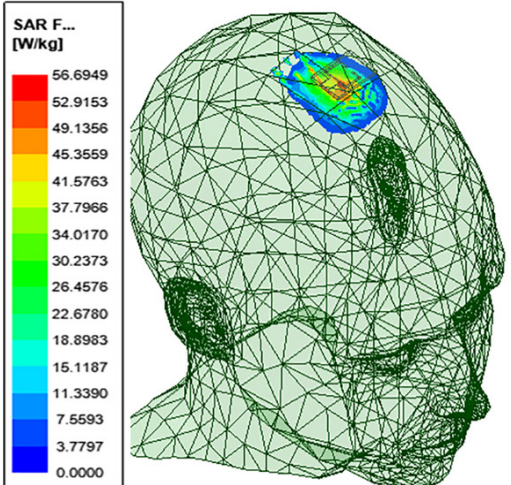

(c)

Fig. 14. SAR distribution of the antenna without AMC in different part of human body: (a) Hand, (b) chest, (c) head.

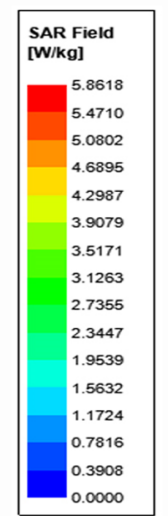

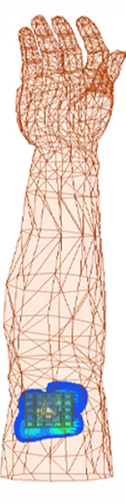

(a)

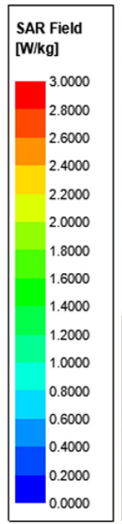

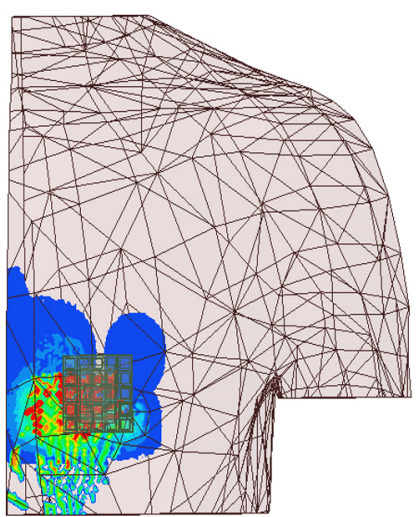

(b)
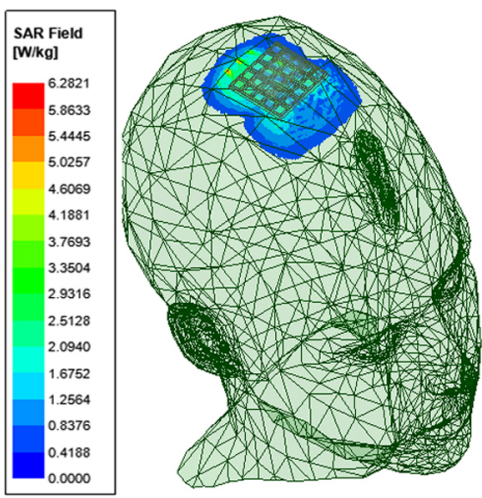

(c)

Fig. 15. SAR distribution of the AMC antenna in different part of human body: (a) hand, (b) chest, (c) head

\begin{tabular}{|c|c|c|c|c|c|c|c|}
\hline \multirow{2}{*}{ Ref } & \multirow{2}{*}{ Size $\mathbf{~ m m}^{3}$} & Reflector & Material used & \multirow{2}{*}{ Flexibility } & \multirow{2}{*}{ Gain dB } & \multicolumn{2}{|c|}{$\begin{array}{c}\text { SAR W/kg (1 W input power and 1 gm } \\
\text { tissue) }\end{array}$} \\
\cline { 5 - 9 } & & & & & Without reflector & With reflector \\
\hline$[8]$ & $102 \times 68 \times 3.6$ & AMC & Pellon fabric & Yes & 6.12 & 47.26 & 0.60 \\
\hline$[13]$ & $\pi \times 50^{2} \times 3$ & EBG & Leather & Yes & -0.55 & 0.312 & 1.12 \\
\hline$[21]$ & $20 \times 26 \times 10$ & FSS and EBG & FR4 & No & 1.5 & --- & -- \\
\hline Our work & $40.5 \times 40.5 \times 6$ & AMC & Leather & Yes & 7.47 & 46.9 & 4.8 \\
\hline
\end{tabular}

Tab. 1. Comparison of the proposed antenna with similar wearable antennas operating in $5.8 \mathrm{GHz}$ band available in literature. 


\section{References}

[1] POON, C. C. Y., ZHANG, Y. T., BAO, S. D. A novel biometrics method to secure wireless body area sensor networks for telemedicine and M-health. IEEE Communications Magazine, 2006, vol. 44, no. 4, p. 73-81. DOI: 10.1109/MCOM.2006.1632652

[2] CHEN, S. Y., KU, T. Y. A low-profile wearable antenna using a miniature high impedance surface for smart watch applications. IEEE Antennas and Wireless Propagation Letters, 2016, vol. 15, p. 1144-1147. DOI: 10.1109/LAWP.2015.2496366

[3] MANOUFALI, M., BIALKOWSKI, K., MOHAMMED, B. J., et al. Near-field inductive-coupling link to power a three-dimensional millimeter-size antenna for brain implantable medical devices. IEEE Transactions on Biomedical Engineering, 2018, vol. 65, no. 1, p. 4-14. DOI: 10.1109/TBME.2017.2778729

[4] ASHYAP, A. Y. I., ABIDIN, Z. Z., DAHLAN, S. H., et al. Compact and low-profile textile EBG-based antenna for wearable medical applications. IEEE Antennas and Wireless Propagation Letters, 2017, vol. 16, p. 2550-2553. DOI: 10.1109/LAWP.2017.2732355

[5] SAHA, P., MITRA, D., PARUI, S. K. A frequency and polarization agile disc monopole wearable antenna for medical applications. Radioengineering, 2020, vol. 29, no. 1, p. 74-80. DOI: $10.13164 /$ re. 2020.0074

[6] VELAN, S., SUNDARSINGH, E. F., KANAGASABAI, M., et al. Dual-band EBG integrated monopole antenna deploying fractal geometry for wearable applications. IEEE Antennas and Wireless Propagation Letters, 2015, vol. 14, p. 249-252. DOI: 10.1109/LAWP.2014.2360710

[7] ALEMARYEEN, A., NOGHANIAN, S. Crumpling effects and specific absorption rates of flexible AMC integrated antennas. IET Microwaves, Antennas \& Propagation, 2018, vol. 12, p. 627-635. DOI: 10.1049/iet-map.2017.0652

[8] ALEMARYEEN, A., NOGHANIAN, S. On-body low-profile textile antenna with artificial magnetic conductor. IEEE Transactions on Antennas and Propagation, 2019, vol. 67, no. 6 , p. 3649-3656. DOI: 10.1109/TAP.2019.2902632

[9] ASHYAP, A. Y. I., ABIDIN, Z. Z., DAHLAN, S. H., et al. Highly efficient wearable CPW antenna enabled by EBG-FSS structure for medical body area network applications. IEEE Access, 2018, vol. 6, p. 77529-77541. DOI: 10.1109/ACCESS.2018.2883379

[10] GAO, G., HU, B., WANG, S., et al. Wearable planar inverted-F antenna with stable characteristic and low specific absorption rate. Microwave and Optical Technology Letters, 2018, vol. 60, p.876-882. DOI: 10.1002/mop.31069

[11] JIANG, Z. H., CUI, Z., YUE, T., et al. Compact, highly efficient, and fully flexible circularly polarized antenna enabled by silver nanowires for wireless body-area networks. IEEE Transactions on Biomedical Circuits and Systems, 2017, vol. 11, no. 4, p. 920-932. DOI: $10.1109 /$ TBCAS.2017.2671841

[12] MANDAL, B., PARUI, S. K. Wearable tri-band SIW based antenna on leather substrate. Electronics Letters, 2015, vol. 51, no. 20, p. 1563-1564. DOI: 10.1049/el.2015.2559

[13] TAK, J., HONG, Y., CHOI, J. Textile antenna with EBG structure for body surface wave enchantment. Electronics Letters, 2015, vol. 51 , no. 15 , p. $1131-1132$. DOI: 10.1049/el.2015.1022

[14] SIMORANGKIR, R. B. V. B., KIOURTI, A, ESSELlE, K. P. UWB wearable antenna with a full ground plane based on PDMSembedded conductive fabric. IEEE Antennas and Wireless Propagation Letters, 2018, vol. 17, no. 3, p. 493-496. DOI: 10.1109/LAWP.2018.2797251
[15] MERSANI, A., LOTFI, O., RIBERO, J. M. Design of a textile antenna with artificial magnetic conductor for wearable applications. Microwave and Optical Technology Letters, 2018, vol. 60 , no. 6 , p. 1343-1349. DOI: $10.1002 /$ mop.31158

[16] Agustine, R., Alves, T., POUSSOT, B., et al. Polymeric ferrite sheet for SAR reduction wearable antennas. Electronics Letters, 2010, vol. 46, no. 3, p. 197-199. DOI: 10.1049/el.2010.3246

[17] PARACHA, K. N., RAHIM, S. K. A., SOH, P. J., et al. A low profile, dual-band, dual polarized antenna for indoor/outdoor wearable application. IEEE Access, 2019, vol. 7, p. 33277-33283. DOI: 10.1109/ACCESS.2019.2894330

[18] EL ATRASH, M., ABDAll, M. A., ELHENNAWY, H. M. A wearable dual-band low profile high gain low SAR antenna AMC-backed for WBAN applications. IEEE Transactions on Antennas and Propagation, 2019, vol. 67, no. 10, p. 6378-6388. DOI: 10.1109/TAP.2019.2923058

[19] RAAD, H. R., ABBOSH, A. I., AL-RIZZO, H. M, et al. Flexible and compact $\mathrm{AMC}$ based antenna for telemedicine applications. IEEE Transactions Antennas and Propagation, 2013, vol. 61, no. 2 , p. 524-531. DOI: 10.1109/TAP.2012.2223449

[20] CHOW, E., YANG, C. L., IRAZOQUI, P. P. Wireless powering and propagation of radio frequencies through tissue. In Agbinya, J. I. (Ed.) Wireless Power Transfer. 1st ed. River Publishers: 2012. Chapter 9, p. 301-336.

[21] EL ARIF, R., TANG, M. C., SU, W. C., et al. Designing a metasurface-based tag antenna for wearable vital sign sensors. In IEEE/MTT-S International Microwave Symposium. Boston (MA, USA), 2019, p. 373-376. DOI: 10.1109/mwsym.2019.8700933

\section{Acknowledgments}

The work of D. Mitra is supported by the Visvesvaraya Young Faculty Research Award through MeitY, Government of India.

\section{About the Authors ...}

Pujayita SAHA received her M.Tech. degree in Radio Physics and Electronics from Calcutta University, India, in 2014. She is currently a Research Scholar in the India Institute of Engineering Science and Technology. Her present research area includes wearable and implantable antenna design for biomedical applications. She has published her work in several esteemed journals and international conferences.

Debasis MITRA (Member, IEEE) received the M.Tech. degree in RF and Microwave Engineering from IIT Kharagpur, Kharagpur, India, in 2009, and the Ph.D. degree from the IIEST, Shibpur, Howrah, India, in 2015. He is currently working as an Assistant Professor with the Department of Electronics and Tele-Communication Engineering, IIEST, Shibpur. He has authored or coauthored more than 75 journals and conference articles. His current research interests include metamaterials, antennas for biomedical application, wireless power transfer, and frequency 
selective surface (FSS) for radar application. Dr. Mitra was a recipient of the Visvesvaraya Young Faculty Research Fellowship Award of Media Lab Asia, under MeitY, Government of India, in 2016, and the Young Faculty Research Award from the Global Alumni Association of Bengal Engineering and Science University, Shibpur, in 2018. He also serves as a reviewer for different journals such as the IEEE Transactions on Vehicular Technology, the IEEE Antennas and Wireless Propagation Letters, the IEEE Transactions on Antennas and Propagation, and the IET Microwaves, Antennas \& Propagation.

Susanta K. PARUI obtained the Master of Engineering and Ph.D. degree in Microwave Engineering from the Bengal Engineering and Science University, Shibpur. He did his Post Doctorial work in the School of ECIT, Queens University in Belfast, Northern Ireland. He is presently associated with the Department of Electronics and Tele-
Communication Engineering, at IIEST, Shibpur, where he is currently a Professor. He has specialization in the area of RF and Microwave Engineering. He has authored over 50 papers in refereed journals and 100 papers in conference proceedings. His current research interests include planar circuits and components, printed antenna and arrays, wearable antenna, dielectric resonator antennas, substrate integrated waveguide, defected ground structure, frequency selective surface, and meta-materials. He executed five research projects from Govt. funding agencies like AICTE, CSIR and DST-SERC and supervised $8 \mathrm{PhD}$ thesis. Dr. Parui received the "India/China Research Fellowship" from the Royal Academy of Engineering, U.K., in the year 2009. $\mathrm{He}$ is a senior member of IEEE and presently member of executive committee of the IEEE Antennas and Propagation/Microwave Theory and Techniques Chapter, Kolkata Section. 